\title{
The Effects of Cost Sharing on Adherence to Medications Prescribed for Concurrent Use: Do Definitions Matter?
}

\author{
Naomi C. Sacks, PhD; James F. Burgess, Jr., PhD; Howard J. Cabral, PhD, MPH; \\ Marie E. McDonnell, MD; and Steven D. Pizer, PhD
}

\begin{abstract}
BACKGROUND: Accurate estimates of the effects of cost sharing on adherence to medications prescribed for use together, also called concurrent adherence, are important for researchers, payers, and policymakers who want to reduce barriers to adherence for chronic condition patients prescribed multiple medications concurrently. But measure definition consensus is lacking, and the effects of different definitions on estimates of cost-related nonadherence are unevaluated.
\end{abstract}

OBJECTIVES: To (a) compare estimates of cost-related nonadherence using different measure definitions and (b) provide guidance for analyses of the effects of cost sharing on concurrent adherence.

METHODS: This is a retrospective cohort study of Medicare Part $D$ beneficiaries aged 65 years and older who used multiple oral antidiabetics concurrently in 2008 and 2009. We compared patients with standard coverage, which contains cost-sharing requirements in deductible (100\%), initial $(25 \%)$, and coverage gap $(100 \%)$ phases, to patients with a low-income subsidy (LIS) and minimal cost-sharing requirements. Data source was the IMS Health Longitudinal Prescription Database. Patients with standard coverage were propensity matched to controls with LIS coverage. Propensity score was developed using logistic regression to model likelihood of Part D standard enrollment, controlling for sociodemographic and health status characteristics. For analysis, 3 definitions were used for unadjusted and adjusted estimates of adherence: (1) patients adherent to All medications; (2) patients adherent on Average; and (3) patients adherent to Any medication. Analyses were conducted using the full study sample and then repeated in analytic subgroups where patients used (a) 1 or more costly branded oral antidiabetics or (b) inexpensive generics only.

RESULTS: We identified 12,771 propensity matched patients with Medicare Part D standard $(N=6,298)$ or LIS $(N=6,473)$ coverage who used oral antidiabetics in 2 or more of the same classes in 2008 and 2009. In this sample, estimates of the effects of cost sharing on concurrent adherence varied by measure definition, coverage type, and proportion of patients using more costly branded drugs. Adherence rates ranged from $37 \%$ (All: standard patients using 1+ branded) to $97 \%$ (Any: LIS using generics only). In adjusted estimates, standard patients using branded drugs had 0.63 $(95 \% \mathrm{Cl}=0.57-0.70)$ and $0.70(95 \% \mathrm{Cl}=0.63-0.77)$ times the odds of concurrent adherence using All and Average definitions, respectively. The Any subgroup was not significant $(\mathrm{OR}=0.89,95 \% \mathrm{Cl}=0.87-1.17)$. Estimates also varied in the full-study sample (All: $\mathrm{OR}=0.79,95 \% \mathrm{Cl}=0.74-0.85$; Average: $\mathrm{OR}=0.83,95 \% \mathrm{Cl}=0.77-0.89$ ) and generics-only subgroup, although costsharing effects were smaller. The Any subgroup generated no significant estimates.

CONCLUSIONS: Different concurrent adherence measure definitions lead to markedly different findings of the effects of cost sharing on concurrent adherence, with All and Average subgroups sensitive to these effects. However, when more study patients use inexpensive generics, estimates of these effects on adherence to branded medications with higher costsharing requirements may be diluted. When selecting a measure definition, researchers, payers, and policy analysts should consider the range of medication prices patients face, use a measure sensitive to the effects of cost sharing on adherence, and perform subgroup analyses for patients prescribed more medications for which they must pay more, since these patients are most vulnerable to cost-related nonadherence.

J Manag Care Spec Pharm. 2015;21(8):678-87

Copyright $\odot 2015$, Academy of Managed Care Pharmacy. All rights reserved.

\section{What is already known about this subject}

Increasing numbers of patients with chronic diseases are prescribed multiple medications for concurrent use.

Different concurrent adherence measures categorize the same patients as adherent or nonadherent and generate markedly different adherence rates.

\section{What this study adds}

Among elderly diabetes patients, cost-related nonadherence estimates varied according to concurrent adherence measure definition and patients' cost-sharing requirements.

The "All" measure, which considered patients adherent only when they used every medication, was most sensitive to costrelated nonadherence.

The "Average" measure, which considered patients adherent when they were adherent to all prescribed medications on average, was useful for evaluating cost-related nonadherence in the aggregate. The "Any" measure, which considered patients adherent when they used any medication as prescribed, was insensitive to costrelated nonadherence in this study sample.

$\mathrm{M}$ edication adherence, or using a medication as prescribed, is a key component in chronic condition management. ${ }^{1-7}$ Nonadherence is associated with poorer health outcomes and higher overall health care expenditures, with a recent estimate of $\$ 110$ billion in annual avoidable nonadherence costs in the United States. ${ }^{1,7-12}$ Given its importance to patients' well-being, and its potential to reduce health care costs, medication adherence has recently been added to the Centers for Medicare and Medicaid Services' Five- 
Star Quality Rating System for health plans and health care providers, and medication adherence measures are now part of the Health Plan Employer Data and Information Set (HEDIS) health plan quality reporting for older adults..$^{13-14}$

Accurate identification of the factors that affect medication adherence is important to payers, providers, and policymakers interested in improving medication adherence. Numerous studies suggest that patient cost sharing is an important factor, with patients less adherent when their cost-sharing requirements are greater..$^{8-9,11,15-19}$ Studies of the Medicare Part D coverage gap (the "doughnut hole"), for example, have shown that patients reduced their medication use when they reached the doughnut hole and were responsible for the full costs of their prescription medications. ${ }^{11,17-22}$ Therefore, the phase-out of the doughnut hole, as part of the Affordable Care Act, is expected to improve medication adherence among Medicare Part D beneficiaries. Although many cost-related nonadherence studies have focused on a single medication, or medication class, increasing numbers of patients with chronic conditions are prescribed multiple medications for use together. Therefore, accurately evaluating the effects of cost sharing on adherence to all medications that patients use is increasingly important for measuring and improving medication adherence.

Studies of the effects of cost sharing on concurrent adherence face a number of methodological challenges, however. Patients treated for the same condition can face different cost-sharing requirements, even when they have the same prescription medication coverage. Most prescriptions filled in the United States are for inexpensive generics. In 2013, for example, $85 \%$ of prescription fills were for generics, and over threequarters of fills had copayments of $\$ 10$ or less. Additionally, medications prescribed for common chronic conditions are available at retail pharmacies as $\$ 4$ cash generics. ${ }^{23}$ By contrast, branded drugs, including those with no generic alternatives, can carry higher cost-sharing requirements and are often on formulary tiers with higher copayments than most generics. ${ }^{22-25}$ Consequently, cost sharing would be expected to have a minimal effect on concurrent adherence for patients who are prescribed only generic medications, while those who are prescribed branded medications could be vulnerable to costrelated nonadherence. Among patients with standard Medicare Part D coverage, for example, Joyce et al. (2013) found modest reductions $(3 \%-4 \%)$ in the use of generic medications in the doughnut hole and greater reductions (8\%-12\%) in the use of branded drugs. ${ }^{22}$ Evaluations that assume that all patients face consistent cost-sharing requirements for all medications may be insensitive to the effects of cost sharing on patients who use branded drugs.

At the same time, formal consensus on the best method for measuring concurrent adherence is lacking. Measures of adherence to individual medications that use administrative data, such as proportion of days covered (PDC), calculate the proportion of days in a measurement period that patients have their prescribed medication on hand. ${ }^{26-29}$ These measures are highly correlated with other methods of measuring adherence. ${ }^{30}$ Concurrent adherence measures build on these individual measures, calculating a PDC that reflects all medications that patients are prescribed for use together. However, definitions vary, with patients considered adherent when they are adherent to any of their medications, ${ }^{8,31}$ when they are adherent to all their medications, ${ }^{32}$ or when they are adherent on average. ${ }^{9,33}$ These definitions reflect different constructs of adherence: the Any measure is the most generous and provides the lowest threshold for considering patients adherent, while the All measure is the most rigorous. Not surprisingly, these different definitions categorize the same patients as adherent or nonadherent and generate markedly different estimates of the proportions of patients considered adherent. ${ }^{30,34}$ Consequently, they would be expected to generate different estimates of the effects of cost sharing on concurrent adherence. The effects of measure definition on estimates of cost-related nonadherence, however, are unevaluated.

In the research reported here, we compared estimates of the effects of cost sharing on concurrent adherence using measure definitions from recent peer-reviewed published studies. We hypothesized that these definitions would generate estimates of cost-related nonadherence that differed in magnitude and significance. We further hypothesized that these differences would be greater when more patients used branded medications and smaller for patients using only inexpensive generics.

\section{Methods}

\section{Study Design}

We used a retrospective cohort study design to evaluate the effects of measure definition on cost-related nonadherence estimates. We focused on oral antidiabetic medications, which are grouped into classes, with drugs from different classes prescribed for concurrent use and drugs from the same class not typically prescribed together. ${ }^{35-38}$ In 2009, our study year, 2 of these classes were dominated by generic prescription fills, accounting for $75 \%$ of all oral antidiabetic prescriptions; we refer to these classes as "generic." Two other classes accounted for an additional 17\% of all oral antidiabetic fills and contained only prescription fills for branded drugs; we refer to these classes as "branded" (Appendix A, available in online article). Mean prescription prices, independent of patient cost-sharing requirements, were $\$ 13-\$ 15$ for drugs in the generic classes but more than $\$ 200$ in the branded classes. ${ }^{37}$ To evaluate the effects of cost sharing on concurrent adherence to oral antidiabetics, we compared patients with Medicare Part D standard coverage (Standard) with those with low-income subsidy (LIS) coverage. The standard Medicare Part D prescription drug benefit has cost-sharing requirements that change through coverage year phases, 
with patients in 2009 responsible for $100 \%$ of their medication costs in a deductible phase, $25 \%$ in an initial coverage phase, and $100 \%$ in the doughnut hole. Thus, Standard diabetes patients would have paid $\$ 13-\$ 15$ for generic oral antidiabetics in the deductible and doughnut hole and about $\$ 4$ in the initial coverage phase; their cost-sharing requirements would have exceeded $\$ 200$ for branded oral antidiabetics in the deductible and doughnut hole and $\$ 50$ in the initial coverage phase. Consequently, Standard patients who used more than 1 oral antidiabetic could have faced different combinations of costsharing requirements, depending on whether they used only generic, generic and branded, or only branded oral antidiabetics. By contrast, cost-sharing requirements for LIS patients were minimal and could not exceed $\$ 2.40$ for generic and $\$ 6.00$ for branded prescriptions throughout the 2009 coverage year. ${ }^{38}$

\section{Data Source}

Our data source was the IMS Health Longitudinal Prescription Database, which contained de-identified patient data for over $60 \%$ of the prescriptions filled in the United States as of 2009. The database includes information on prescription drug product, form, and strength; retail pharmacy; payer (e.g., cash, commercial insurer, Medicare, or Medicaid); and patient age and gender.

\section{Study Sample}

We studied Medicare Part D beneficiaries aged 65 years and older. Because we were interested in patients who were familiar with the cost-sharing requirements for their medications, we limited our study sample to those who filled prescriptions for oral antidiabetics in the same class in the baseline and study years (2008 and 2009). Patients who switched from 1 class of medication to another or who started an oral antidiabetic medication in a new class during the study year were excluded, as were those who died or entered nursing homes. To address covariate imbalance between Standard and LIS patients, we developed a propensity score that modeled the likelihood of Part D standard plan enrollment in order to identify Standard and LIS patients who were similar on all observable characteristics. We used logistic regression with Standard enrollment (yes/no) as the outcome and demographic and health status covariates as independent variables. We then conducted nearest neighbor propensity score matching via logistic regression.

Our final sample for this study was a subset of propensitymatched patients who filled prescriptions for oral antidiabetic medications in at least 2 of the same classes in the baseline (2008) and study (2009) years. Figure 1 provides a graphic representation of our study sample selection. We used the full sample to test our hypothesis that estimates of the effects of cost sharing on concurrent adherence would vary according to the concurrent adherence measure definition. To assess whether these differences would be greater for patients using branded and smaller for those using only generic oral antidiabetics, we identified 2 analytic subgroups: (1) patients who used at least 1 branded oral antidiabetic and (2) patients who used only generic oral antidiabetics. We have described our inclusion requirements and propensity matching in detail in previously published research. ${ }^{39}$

\section{Concurrent Adherence Outcome and Model Covariates}

Concurrent Adherence. We used 3 definitions from peerreviewed studies to calculate unadjusted and adjusted measures of concurrent adherence. ${ }^{8,10,31}$ The first definition requires patients to be adherent to All of their medications; the second definition requires that patients are adherent, on Average; and the third definition requires that patients are adherent to Any of their medications-this definition is referred to as "At Least 1 " in other literature. ${ }^{30,34}$

To calculate All and Average concurrent adherence, we first measured adherence at the single oral antidiabetic class level, following methods recommended by the Pharmacy Quality Alliance and used in multiple studies to calculate adherence to individual medications. . $^{8,16,18-19,29,40}$ First, we counted days supplied over the full study year as the sum of days supplied for each fill for a drug in each oral antidiabetic class, plus any days remaining from previous year fills, truncated at year end. We counted medication switches within the same class (e.g., from a branded to a generic or from one generic to another) as medication use within that class. Next, we calculated the PDC as the ratio of days supplied to calendar days in our observation period, which was the full study year. Using the All definition, we considered patients adherent when their PDC was 0.80 or above for each medication; using the Average definition, we considered patients adherent when the mean PDC across all of their oral antidiabetic medications was at least 0.80 - the 0.80 threshold is used in many studies to identify patients as adherent or nonadherent. ${ }^{5,8,10,16,18-19,26,29}$ To calculate Any concurrent adherence, we counted days on which any oral antidiabetic was available and considered patients adherent when the PDC calculated was at least 0.80 . This Any definition did not require that patients have a specific oral antidiabetic or specific class oral antidiabetic available during our measurement period. In Figure 2, we show how a patient's adherence would be rated differently based on the definition used.

Covariates. We used prescription fill information to identify patient gender, age, baseline year risk score, comorbid medication, and insulin use. We used a Chronic Disease Score as a measure of patient health status in the baseline year. ${ }^{41-42}$ The Chronic Disease Score is a well-validated comorbidity tool that uses pharmacy fill data to identify patient risk in different patient groups. ${ }^{17,42-45}$ Our comorbidities included hypertension, hyperlipidemia, cardiovascular disease, and depression, which are conditions that often accompany diabetes. We derived 
The Effects of Cost Sharing on Adherence to Medications Prescribed for Concurrent Use:

Do Definitions Matter?

\section{FIGURE 1 Cohort of Diabetes Patients}

416,034 Medicare Part D patients with OAD prescriptions in 2008 and 2009

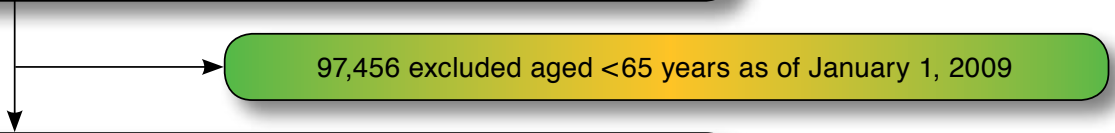

318,578 patients with OAD prescriptions in 2008 and 2009, aged $\geq 65$ years as of January 1, 2009

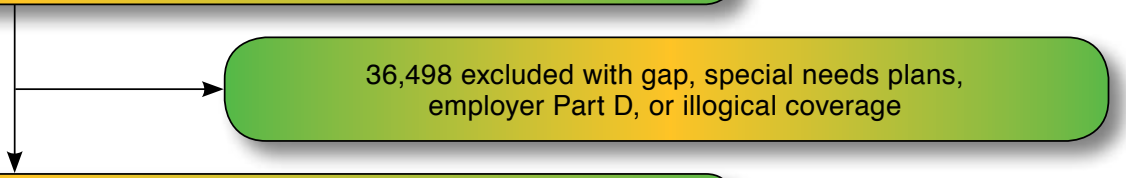

282,080 patients with OAD prescriptions in 2008 and 2009 , aged $\geq 65$ years, and meet coverage restrictions

2,969 excluded without fills in same class in 2008 and 2009

279,111 patients with OAD fills in same class in 2008 and 2009 , aged $\geq 65$ years, and meet coverage restrictions

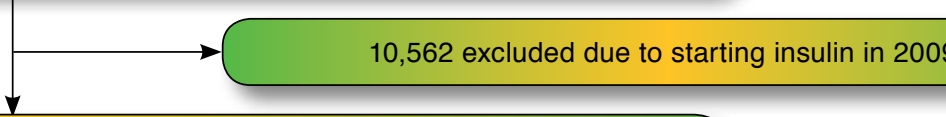

268,549 patients with OAD fills in same class in 2008 and 2009

aged $\geq 65$ years, meet coverage restrictions, and no new study year insulin

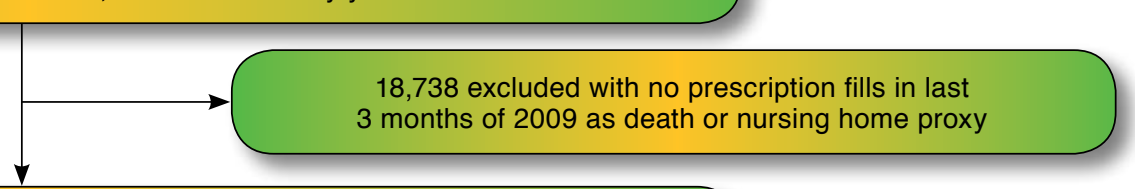

249,811 patients with OAD fills in same class in 2008 and 2009 , aged $\geq 65$ years,

meet coverage restrictions, no new study year insulin, and at least 1 fill in Q4 2009

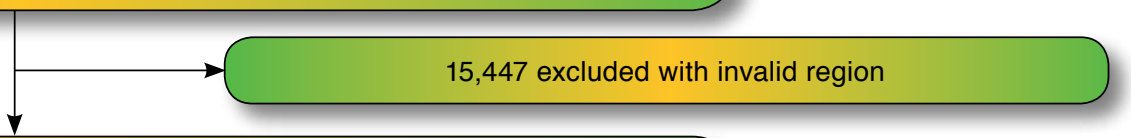

234,364 patients with OAD fills in same class in 2008 and 2009 , aged $\geq 65$ years, meet coverage restrictions, no new study year insulin, and valid region

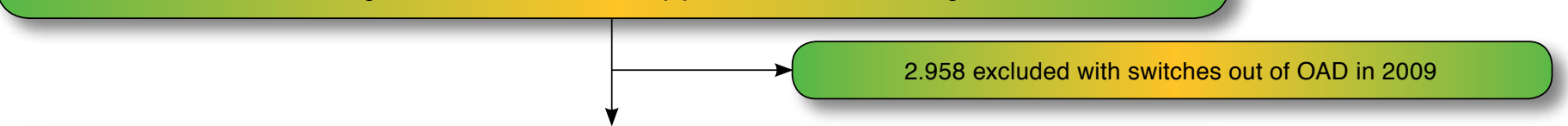

231,406 patients with OAD fills in same class in 2008 and 2009 , aged $\geq 65$ years, meet coverage restrictions, no new study year insulin, valid region, and no study year switches

38,054 propensity-matched patients with Standard or LIS Part D coverage

12,771 propensity-matched patients with $2+$ same class OADs in 2008 and 2009

LIS =low-income subsidy; OAD = oral antidiabetic; $Q=$ quarter 


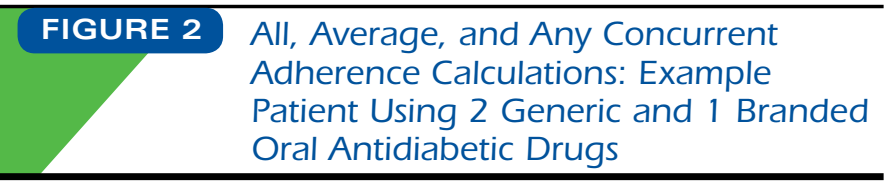

Time Period Start

Time Period End

Medication 1 Generic antidiabetic days supplied $=338$ $\mathrm{PDC}=0.94$

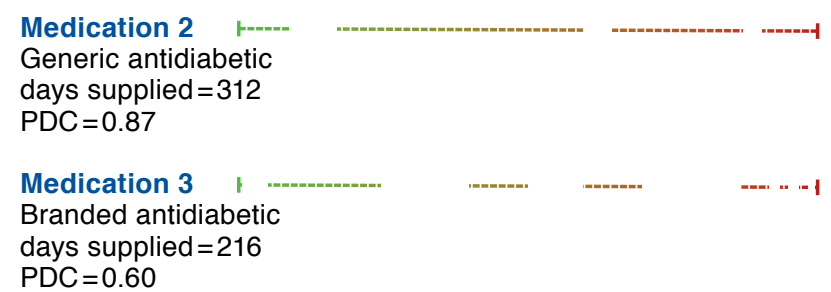

Note: Number of days on which any of medication 1, 2, or 3 is available $=360$.

\begin{tabular}{|c|c|c|c|}
\hline $\begin{array}{l}\text { Concurrent } \\
\text { Adherence } \\
\text { Measure }\end{array}$ & \multicolumn{2}{|c|}{ Calculation } & $\begin{array}{l}\text { Is Patient } \\
\text { Considered } \\
\text { Adherent? }\end{array}$ \\
\hline$\overline{\text { All }}$ & $\begin{array}{l}\text { (Medication } 1 \text { days supplied/ } \\
\text { calendar days) } \geq 0.80 \text { AND } \\
\text { (Medication } 2 \text { days supplied/ } \\
\text { calendar days) } \geq 0.80 \text { AND } \\
\text { (Medication } 3 \text { days supplied/ } \\
\text { calendar days } \geq 0.80 \text { ) }\end{array}$ & $\begin{array}{l}\operatorname{PDC} 1=324 / 360= \\
0.94 \geq 0.80 \\
\operatorname{PDC} 2=312 / 360= \\
0.87 \geq 0.80 \\
\operatorname{PDC} 3=210 / 360= \\
0.60<0.80\end{array}$ & No \\
\hline Average & $\begin{array}{l}\text { [(Medication } 1 \text { days supplied/ } \\
\text { calendar days) }+ \\
\text { (Medication } 2 \text { days } \\
\text { supplied/calendar days)+ } \\
\text { (Medication } 3 \text { days supplied/ } \\
\text { calendar days)]/3 } 30.80\end{array}$ & $\begin{array}{l}{[(324 / 360)+} \\
(312 / 360)+ \\
(216 / 360)]= \\
{[(0.94+0.87+} \\
0.60)] / 3= \\
0.80 \geq 0.80\end{array}$ & Yes \\
\hline Any & $\begin{array}{l}\text { Days on which any of } \\
\text { Medication } 1,2 \text {, or } 3 \text { is } \\
\text { available/calendar days } \\
\geq 0.80\end{array}$ & $\begin{array}{l}360 / 360= \\
1.00>0.80\end{array}$ & Yes \\
\hline
\end{tabular}

$P D C=$ proportion of days covered.

additional sociodemographic information using the retail pharmacy ZIP code. We have described all independent variables in detail in previously published research. ${ }^{39}$

\section{Analyses}

Unadjusted Analyses. We calculated unadjusted adherence rates using each measure definition for the entire study sample and, separately, by Part D coverage type (Standard or LIS). We then repeated these analyses in the 2 subgroups that would have faced different cost-sharing requirements because of the mix of medications they used, that is, the subgroup who used at least 1 branded oral antidiabetic and the subgroup who used only generics. We used each measure definition to calculate

\section{TABLE 1 Study Sample Characteristics ${ }^{\mathrm{a}}$}

\begin{tabular}{|c|c|c|c|c|}
\hline \multirow[b]{2}{*}{ Male, n (\%) } & \multicolumn{2}{|c|}{$\begin{array}{c}\text { Part D Standard } \\
\text { Cost Sharing } \\
\text { N }=6,298\end{array}$} & \multicolumn{2}{|c|}{$\begin{array}{c}\text { Part D Subsidized } \\
\text { (LIS) } \\
\mathrm{N}=6,475\end{array}$} \\
\hline & 2,391 & (38) & 2,406 & (37) \\
\hline Mean age (SD) & 73.9 & $(6.18)$ & 73.7 & $(11.48)$ \\
\hline \multicolumn{5}{|l|}{ Region, n (\%) } \\
\hline East & 1,816 & $(29)$ & 1,888 & $(29)$ \\
\hline Midwest & 1,016 & (16) & 1,039 & (16) \\
\hline South & 2,482 & (38) & 2,445 & (38) \\
\hline West & 984 & $(16)$ & 1,101 & $(17)$ \\
\hline Mean income, in thousands (SD) & $\$ 42.4$ & $(15.2)$ & $\$ 42.2$ & $(14.8)$ \\
\hline Mean risk score (SD) & 5.52 & $(2.56)$ & 5.58 & $(2.60)$ \\
\hline \multicolumn{5}{|l|}{ Comorbid medication use, n (\%) } \\
\hline $\begin{array}{l}\text { Hypertension/cardiovascular } \\
\text { disease }\end{array}$ & 5,970 & (95) & 6,116 & (94) \\
\hline Hyperlipidemia & 5,387 & $(85)$ & 5,526 & $(85)$ \\
\hline Mental health & 2,773 & $(44)$ & 2,958 & $(46)$ \\
\hline Medication burden, mean (SD) & 22.3 & $(10.7)$ & 22.8 & $(11.4)$ \\
\hline \multicolumn{5}{|l|}{ OAD use at baseline, $\mathrm{n}(\%)$} \\
\hline 2 OADs & 4,135 & $(66)$ & 4,392 & $(68)$ \\
\hline $3+$ OADs & 2,163 & (34) & 2,081 & $(32)$ \\
\hline Insulin use, $\mathrm{n}(\%)$ & 835 & $(13)$ & 893 & $(14)$ \\
\hline \multicolumn{5}{|l|}{ Severity, n (\%) } \\
\hline 2 OADs, no insulin & 3,644 & (58) & 3,823 & (59) \\
\hline $3+$ OADs and/or insulin & 2,654 & $(42)$ & 2,650 & $(41)$ \\
\hline \multicolumn{5}{|l|}{ Baseline OAD use, $\mathrm{n}(\%)$} \\
\hline Biguanides (primarily generic) & 4,868 & $(77)$ & 4,968 & $(77)$ \\
\hline $\begin{array}{l}\begin{array}{l}\text { Sulfonylureas/glinides } \\
\text { (primarily generic) }\end{array} \\
\end{array}$ & 5,135 & $(82)$ & 5,304 & $(82)$ \\
\hline Glitazones (branded only) & 2,448 & (39) & 3,499 & (39) \\
\hline DPP-4 inhibitors (branded only) & 715 & $(11)$ & 708 & $(11)$ \\
\hline $\begin{array}{l}\text { Combination products } \\
\text { (branded and generic) }\end{array}$ & 545 & (9) & 569 & (9) \\
\hline $\begin{array}{l}\text { Alpha-glucosidase inhibitors } \\
\text { (branded and generic) }\end{array}$ & 81 & (1) & 76 & (1) \\
\hline $1+$ generics & 6,045 & (96) & 6,132 & $(95)$ \\
\hline $1+$ branded & 2,989 & $(47)$ & 3,014 & $(49)$ \\
\hline generics only & 2,990 & $(47)$ & 3,188 & $(47)$ \\
\hline $\begin{array}{l}1+\text { nonprimarily generic; } \\
0 \text { branded }\end{array}$ & 319 & (5) & 271 & (4) \\
\hline
\end{tabular}

aEstimates reflect patients who used OADs in the same class in 2008 and 2009. Newly added OADs in 2009 are not reflected in these numbers.

DPP-4 = dipeptidyl peptidase 4; LIS = low-income subsidy; OAD = oral antidiabetic; $S D=$ standard deviation.

adherence rates in each subgroup, both overall and stratified by coverage type.

Adjusted Analyses. We used logistic regression to estimate the effects of standard coverage on concurrent adherence, controlling for sociodemographic and health status factors. We ran our model separately using each concurrent adherence definition as the outcome. We conducted all analyses for the entire study sample and then repeated them for the 2 analytic subgroups. 


\section{FIGURE 3}

Unadjusted Concurrent Adherence Rates Using Different Definitions: All Patients and Patients by Coverage Type

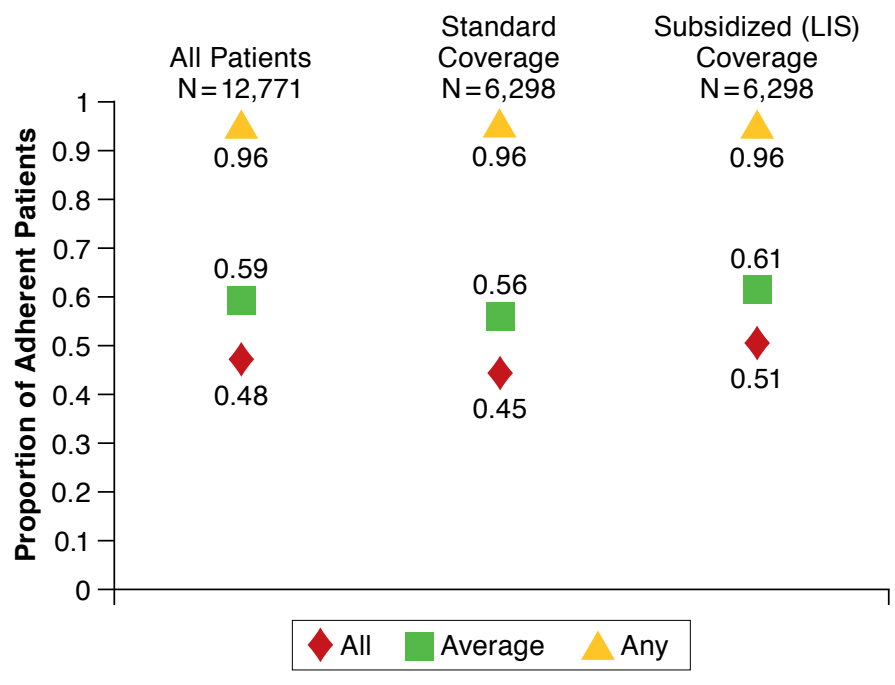

LIS = low-income subsidy.

\section{Results}

\section{Patient Sample}

The analytic sample was a subset of propensity-matched patients $(\mathrm{N}=38,054)$ who used oral antidiabetics in 2 or more of the same classes in 2008 and 2009 ( $\mathrm{N}=12,771$; Standard: 6,298; LIS: $N=6,473$ ). These Standard and LIS patients were similar on all observable characteristics (Table 1). Nearly all (95\%) used at least 1 generic oral antidiabetic; $47 \%(\mathrm{~N}=6,003)$ used at least 1 branded; and 48\% (N=6,178) used only generics. A small proportion ( $\mathrm{N}=590 ; 5 \%)$ used oral antidiabetics in other classes. Details on the characteristics of the unmatched study sample and the full set of propensity-matched patients are available in Appendix B (available in online article) and in previously published research. ${ }^{39}$

\section{Unadjusted Adherence Rates}

As shown in Figure 3 and Figure 4, unadjusted adherence rates varied considerably, depending on measure definition, coverage type (Standard vs. LIS), and medication mix. Using the All definition, $48 \%$ of all study patients were considered adherent, while adherence rates were 59\% and 96\% using the Average and Any definitions, respectively. The range of estimates was wider for Standard patients (All: 45\%; Average: 56\%; Any: 96\%), but narrower for LIS (All: 51\%; Average: 59\%; Any: 96\%; Figure 3). In the subgroup of patients using branded oral antidiabetics, however, smaller proportions of Standard patients were considered adherent using the All (37\%) and Average
(51\%) definitions, while adherence rates for LIS patients were similar to those in the overall study group (All: 48\%; Average: $59 \%$ ). By contrast, in the subgroup using only generics, concurrent adherence rate estimates varied by measure definition only (All: 55\%; Average: 64\%) and were nearly identical by coverage type (Figure 4). Notably, using the Any definition, adherence rates were nearly identical, regardless of coverage type and medication mix (96\%-97\%).

\section{Adjusted Estimates}

Table 2 shows estimates of the effects of cost sharing on concurrent adherence from the logistic regression models. Using the All definition, the odds of adherence for patients with Standard coverage, compared with LIS, were 0.79 (95\% confidence interval $[\mathrm{CI}]=0.74-0.85$ ). Using the Average definition, these odds were slightly higher, although the CIs overlapped (odds ratio $[\mathrm{OR}]=0.83,95 \% \mathrm{CI}=0.77-0.89$ ). Using the Any definition, patients with Standard coverage had slightly higher odds of adherence, but the estimate was not statistically significant $(\mathrm{OR}=1.04,95 \% \mathrm{CI}=0.87-1.24)$.

The odds of adherence estimated using the All and Average definitions were smaller for the subgroup of patients using at least 1 branded oral antidiabetic, however. Using the All definition, Standard patients had 0.63 (95\% CI = 0.57-0.70) times the odds of adherence, compared with LIS, while using the Average definition, patients had $0.70(95 \% \mathrm{CI}=0.63-0.77)$ times the odds, although the CIs in these All and Average estimates also overlapped. The estimate generated using the Any definition was not statistically significant $(\mathrm{OR}=0.89,95 \% \mathrm{CI}=0.68-1.12)$.

Part D Standard coverage did not have a significant effect on concurrent adherence in the subgroup of patients using generic oral antidiabetics only (All: $\mathrm{OR}=0.98,95 \% \mathrm{CI}=0.89$ 1.09; Average: $\mathrm{OR}=1.00,95 \% \mathrm{CI}=0.90-1.11$; Any: $\mathrm{OR}=1.21$, 95\% CI $=0.93-1.58)$.

\section{Discussion}

When we compared concurrent adherence definitions from peer-reviewed published studies, we found that estimates of the effects of cost sharing on concurrent adherence varied depending on measure definition and the proportion of analytic sample patients using more expensive branded medications. In unadjusted analyses, adherence rates ranged from $37 \%$ to $96 \%$, depending on measure definition, coverage type, and medication mix. In adjusted analyses, the All definition was most sensitive to the effects of cost sharing on concurrent adherence, with these effects strongest in the subgroup using at least 1 branded oral antidiabetic. The Average definition was also sensitive to these effects. But the dominance of generic oral antidiabetic use, coupled with higher generic oral antidiabetic PDC ratios, raised average adherence rates, shifting cost-related nonadherence estimates towards the null. The estimates generated using the All and Average definitions were close, however, 


\section{FIGURE 4 Unadjusted Adherence Rates: Patients Using Generic OADs}

Only Versus Patients Using 1+ Branded OADs

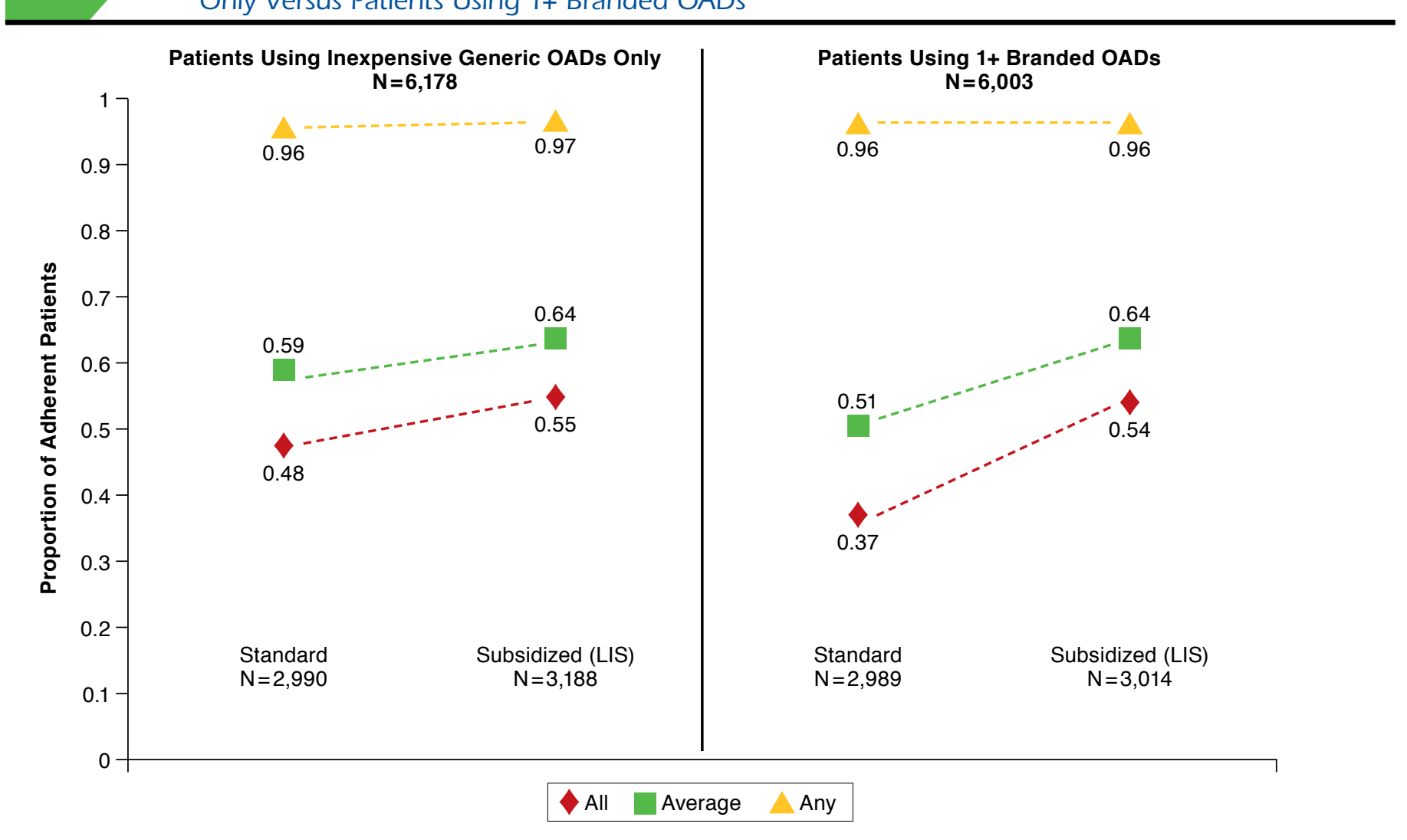

LIS = low-income subsidy; OAD=oral antidiabetic.

and the CIs on these estimates overlapped. By contrast, the Any definition was insensitive to the effects of cost sharing on adherence with less commonly used and more costly medications.

Choudhry et al. (2009) and Basak et al. (2014) found that different definitions lead to strikingly different estimates of the proportion of patients considered adherent. ${ }^{30,34}$ Our results extend these findings, demonstrating that different measure definitions generate markedly different estimates of cost sharing on concurrent adherence. They also contribute to our understanding of these effects when medications used to treat common chronic conditions are available as inexpensive generics. Using the All and Average definitions, we found that cost sharing had no effect on concurrent adherence for patients using only generics. However, both definitions generated significant estimates of these effects in the full study sample, where nearly half of all patients used at least 1 branded oral antidiabetic and even larger effects in the subgroup of patients who all used at least 1 branded medication. Evaluations of the effects of cost sharing on concurrent adherence may assume that all patients face consistent cost-sharing requirements for all medications they use, with minimal variation within and across different patients' medication regimens. Our results suggest that the adverse effects of cost sharing on patients using drugs for which cost-sharing requirements are higher can be diluted when large numbers of study sample patients use only generics with low cost-sharing requirements.

Our results also provide measure selection guidance for such studies. From a strictly clinical perspective, a measure that highlights the effects of cost on adherence to each regimen medication would provide the most accurate results regarding the effectiveness of an intervention that targets cost-related nonadherence. The All definition is best suited for this purpose, but if a payer or provider is interested in the effects of a benefit design change on medication adherence, widespread inexpensive generic medication use could dilute estimates of these effects, since the change could affect only a small number of patients. Analyses that take into account the prices that different patients face, potentially focusing on patients who use more costly medications, would be more likely to uncover such effects. 
The Effects of Cost Sharing on Adherence to Medications Prescribed for Concurrent Use:

Do Definitions Matter?

TABLE 2 Adjusted Odds Ratios for Effects of Cost Sharing on Concurrent

Adherence: Part D Standard Versus Subsidized (LIS) Coverage ${ }^{a}$

\begin{tabular}{|c|c|c|c|c|}
\hline \multirow[b]{2}{*}{ Patient Sample } & \multirow{2}{*}{$\begin{array}{l}\text { Number of } \\
\text { Patients }\end{array}$} & All Adherenceb & Average Adherence & Any Adherence ${ }^{c}$ \\
\hline & & \multicolumn{3}{|c|}{ Point Estimate $(95 \% \mathrm{CI}), P$ Value } \\
\hline All patients & 12,771 & $0.79(0.74-0.85),<0.0001$ & $0.83(0.77-0.89),<0.0001$ & $1.04(0.87-1.24), \quad 0.6900$ \\
\hline Patients using $1+$ branded OADs & 6,003 & $0.63(0.57-0.70),<0.0001$ & $0.70(0.63-0.77),<0.0001$ & $0.89(0.68-1.17), \quad 0.4100$ \\
\hline Patients using generic OADs only & 6,178 & $0.98(0.89-1.09), \quad 0.7600$ & $1.00(0.90-1.11), \quad 0.9700$ & $1.21(0.94-1.58), \quad 0.1700$ \\
\hline \multicolumn{5}{|c|}{$\begin{array}{l}{ }^{a} \text { Adjusted for sociodemographic, health status, and non-OAD medication use variables. } \\
{ }^{b} \text { Concurrent adherence measured as adherence to each class of } O A D \text { medication, with adherence defined as } P D C \geq 0.80 \text {. } \\
{ }^{c} \text { Concurrent adherence measured as adherence to any } O A D \text { medication, with adherence defined as } P D C \geq 0.80 \text {. } \\
C I=\text { confidence interval; LIS=low-income subsidy; OAD = oral antidiabetic; } P D C=\text { proportion of days covered. }\end{array}$} \\
\hline
\end{tabular}

The Average definition could be appropriate for studies evaluating cost-related nonadherence in the aggregate. While it may be less meaningful clinically, this measure would reflect the majority of patients using generics, providing information relevant to a high-level policy assessment. The utility of the Any definition is questionable for patients who are continuing users of multiple medications. In an evaluation of the effects of cost sharing on concurrent antidiabetic, lipid lowering, and antihypertensive medication adherence, for example, patients using more medications could be more likely to have at least 1 medication on hand $80 \%$ of the time, compared with those using fewer medications, simply because of the numbers of drugs they are prescribed.

\section{Limitations}

This study has limitations. We evaluated only adherence definitions that use an interval-based time frame, and our study sample included only elderly patients with Medicare Part D coverage. However, our results are consistent with Choudhry et al., who found that the Any definition identified nearly all commercially insured patients using oral antidiabetics as adherent, compared with the All definition, which identified fewer than half. ${ }^{30}$ Another limitation is that we only looked at adherence to oral antidiabetic medications. However, inexpensive generic medications are widely prescribed for other common chronic conditions, such as cardiovascular disease, hypertension, and hyperlipidemia, and fewer patients use more costly branded products. ${ }^{24}$ Therefore, patients with these conditions can face cost-sharing requirements that vary according to the mix of branded and generic medications they use together, as they would have for diabetes patients with Part D standard coverage in our study sample. We did not, however, have access to the actual medication prices that patients faced, which could have varied across Medicare Part D plans. Nonetheless, our results are consistent with studies of the Medicare Part D benefit that find that cost sharing has a greater negative effect on adherence to branded drugs, particularly in the doughnut hole. ${ }^{22,23,39}$ Finally, our study sample was limited to patients who were continuing users of oral antidiabetic medications in the same class and did not include patients who received but did not fill prescriptions or who started new medications in our study year. But, higher cost sharing has been shown to adversely affect medication uptake, and we would expect concurrent adherence measures to vary in their sensitivity to cost-related nonadherence among patients with new prescriptions for medications with different cost-sharing requirements.

\section{Conclusions}

Different measure definitions generate varying estimates of the effects of cost sharing on concurrent adherence, with conflicting implications for benefit design and policy modifications. Studies of cost-related nonadherence, including those that assess the impact of benefit design changes, should consider variations in cost-sharing requirements for medications that study sample patients use, as well as treatment guidelines and analytic goals. When patients face different medication prices, analyses of subgroups using more costly medications are recommended for precise assessments of the effects of cost sharing on adherence and successful implementation of benefit design changes that target adherence improvements.

\section{Authors}

NAOMI C. SACKS, PhD, is Senior Health Economist, Precision for Value, Cambridge, Massachusetts; HOWARD J. CABRAL, PhD, MPH, is Professor, Department of Biostatistics, Boston University School of Public Health, Boston, Massachusetts; and MARIE E. MCDONNELL, MD, is Director, Brigham and Women's Diabetes Program, Brigham and Women's Hospital, Boston, Massachusetts. JAMES F. BURGESS, JR., PhD, is Senior Investigator, Center for Healthcare Organization and Implementation Research, VA Boston Healthcare System, and Professor, Department of Health Policy and Management, Boston University School of Public Health, Boston, Massachusetts. STEVEN D. PIZER, PhD, is Director, Healthcare Financing and Economics, VA Boston Healthcare System, and Associate Professor, Department of Pharmacy Practice, School of Pharmacy and Department of Economics, Northeastern University, Boston, Massachusetts.

AUTHOR CORRESPONDENCE: Naomi C. Sacks, PhD, Precision for Value, 55 Cambridge Pkwy., Ste. 300E, Cambridge, MA 02142 Tel.: 617.299.3003; Fax: 617.812.0815;

E-mail:naomi.sacks@precisionformedicine.com. 


\section{The Effects of Cost Sharing on Adherence to Medications Prescribed for Concurrent Use: Do Definitions Matter?}

\section{DISCLOSURES}

No funding was received for this research. Sacks was employed by IMS Health at the time this study was conducted and used IMS data for this research. There are no other potential conflicts of interest.

Sacks was the only author to have access to the IMS data and was responsible for the overall study design, data analysis, and manuscript drafts. Burgess, Cabral, and Pizer contributed to the study design, intellectual content, and final version of this manuscript. McDonnell provided clinical input during the analysis of study data and clinical review for this manuscript.

\section{ACKNOWLEDGMENTS}

The authors would like to thank Arlene S. Ash, PhD, and Amy K. Rosen, PhD, for their thoughtful comments on earlier versions of this manuscript and their assistance with editing.

\section{REFERENCES}

1. Cherry SB, Benner JS, Hussein MA, Tang SS, Nichol MB. The clinical and economic burden of nonadherence with antihypertensive and lipid-lowering therapy in hypertensive patients. Value Health. 2009;12(4):489-97.

2. DiMatteo MR, Giodani PJ, Lepper HS, Croghan TW. Patient adherence and medical treatment outcomes: a meta-analysis. Med Care. 2002;40(9):794-811.

3. Encinosa WE, Bernard D, Dor A. Does prescription drug adherence reduce hospitalizations and costs? The case of diabetes. Adv Health Econ Health Serv Res. 2010;22:151-73.

4. Ho PM, Bryson CL, Rumsfeld JS. Medication adherence: its importance in cardiovascular outcomes. Circulation. 2009;119(23);3028-35.

5. Ho PM, Rumsfeld JS, Masoudi FA, et al. Effect of medication nonadherence on hospitalization and mortality among patients with diabetes mellitus. Arch Intern Med. 2006;166(17):1836-41.

6. Osterberg L, Blaschke T. Adherence to medication. N Engl J Med. 2005;353(5):487-97.

7. Sokol MC, McGuigan KA, Verbrugge RR, Epstein RS. Impact of medication adherence on hospitalization risk and healthcare cost. Med Care. 2005:43(6):521-30

8. Gibson TB, Song X, Alemayehu B, Wang SS, Waddell JL, Bouchard JR, Forma F. Cost sharing, adherence, and health outcomes in patients with diabetes. Am J Manag Care. 2010;16(8):589-600.

9. Hsu J, Price M, Huang J, et al. Unintended consequences of caps on Medicare drug benefits. N Engl J Med. 2006;354(22):2349-59.

10. Roebuck MC, Liberman JN, Gemmill-Toyama M, Brennan TA. Medication adherence leads to lower health care use and costs despite increased drug spending. Health Aff (Millwood). 2011;30(1):91-99.

11. Soumerai SB, McLaughlin TJ, Ross-Degnan D, Casteris CS, Bollini P. Effects of limiting Medicaid drug-reimbursement benefits on the use of psychotropic agents and acute metal health services by patients with schizophrenia. N Engl J Med. 1994;331(10):650-65.

12. IMS Health Institute for Healthcare Informatics. Avoidable costs in U.S. healthcare: the $\$ 200$ billion opportunity from using medicines more responsibly. June 2013. Available at: http://www.imshealth.com/deployedfiles/imshealth/Global/Content/Corporate/IMS\%20Institute/RUOM-2013/ IHII_Responsible_Use_Medicines_2013.pdf. Accessed June 26, 2015.

13. Centers for Medicare and Medicaid Services (CMS). Medicare health \& drug plan quality and performance ratings: 2013 Part C \& Part D technical notes. Available at: http://www.cms.gov/Medicare/Prescription-DrugCoverage/PrescriptionDrugCovGenIn/Downloads/Technical-Notes-2013pdf. Accessed June 26, 2015

14. National Committee for Quality Assurance (NCQA). HEDIS 2014 final NDC lists. Available at: http://www.ncqa.org/HEDISQualityMeasurement/ HEDISMeasures/HEDIS2014/HEDIS2014FinalNDCLists.aspx. Accessed June $26,2015$.
15. Briesacher BA, Gurwitz JH, Soumerai SB. Patients at-risk for cost-related medication nonadherence: a review of the literature. J Gen Intern Med. 2007;22(6):864-71.

16. Doshi JA, Zhu J, Lee BY, Kimmel SE, Volpp KG. Impact of a prescription copayment increase on lipid-lowering medication adherence in veterans. Circulation. 2009;119(3):390-97.

17. Schneeweiss S, Patrick AR, Pedan A, et al. The effect of Medicare Part $D$ coverage on drug use and cost sharing among seniors without prior drug benefits. Health Aff (Millwood). 2009;28(2):w305-16.

18. Polinski JM, Shrank WH, Huskamp HA, Glynn RJ, Liberman JN, Schneeweiss S. Changes in drug utilization during a gap in insurance coverage: an examination of the Medicare Part D coverage gap. PLoS Med. 2011;8(8):e1001075

19. Stuart B, Davidoff A, Erten M, et al. How Medicare Part D benefit phases affect adherence with evidence-based medications following acute myocardial infarction. Health Serv Res. 2013;48(6 Pt 1):1960-77.

20. Hoadley J, Hargrave E, Cubanski J, Neuman T. The Medicare Part D coverage gap: cost and consequences in 2007. The Henry J. Kaiser Family Foundation. August 2008. Available at: https://kaiserfamilyfoundation.files. wordpress.com/2013/01/7811.pdf. Accessed June 26, 2015.

21. Hoadley J, Summer L, Hargrave E, Cubanski J. Understanding the effects of the Medicare Part D coverage gap in 2008 and 2009: costs and consequences prior to improvements in coverage established by the 2010 health reform law. The Henry J. Kaiser Family Foundation. September 2011. Available at: https://kaiserfamilyfoundation.files.wordpress.com/2011/08/8221-understanding-the-effects-of-the-medicarepart-d-coverage-gap-in-2008-and-2009.pdf. Accessed June 26, 2015.

22. Joyce GF, Zissimopoulos J, Goldman DP. Digesting the doughnut hole. $J$ Health Econ. 2013;32(6):1345-55

23. Hoadley JF, Merrell K, Hargrave E, Summer L. In Medicare Part D plans, low or zero copays and other features to encourage the use of generic statins work, could save billions. Health Aff (Millwood). 2012;31(10):2266-75.

24. IMS Institute for Healthcare Informatics. Medicine use and shifting costs of healthcare: a review of the use of medicines in the United States in 2013 April 2014. Available at: http://www.imshealth.com/cds/imshealth/Global/ Content/Corporate/IMS\%20Health\%20Institute/Reports/Secure/IIHI_US_ Use_of_Meds_for_2013.pdf. Accessed June 26, 2015.

25. Hoadley J, Summer L, Hargrave E, Cubanski J, Neuman T. Medicare Part D in its ninth year: the 2014 marketplace and key trends, 2006-2014. The Henry J. Kaiser Family Foundation. August 2014. Available at: http://kff.org/ medicare/report/medicare-part-d-in-its-ninth-year-the-2014-marketplaceand-key-trends-2006-2014. Accessed June 26, 2015.

26. Karve S, Cleves MA, Helm M, et al. Good and poor adherence: optimal cut-point for adherence measures using administrative claims data. Curr Med Res Opin. 2009;25(9):2303-10

27. Martin BC, Wiley-Exley EK, Richards S, Domino ME, Carey TS, Sleath BL. Contrasting measures of adherence with simple drug use, medication switching, and therapeutic duplication. Ann Pharmacother. 2009;43(1):36-44.

28. Andrade SE, Kahler KH, Frech F, et al. Methods for evaluation of medication adherence and persistence using automated databases. Pharmacoepidemiol Drug Saf. 2006;15(8):565-74.

29. Yeaw J, Benner JS, Walt JG, Sian S, Smith DB. Comparing adherence and persistence across 6 chronic medication classes. J Manag Care Pharm. 2009;15(9):728-40. Available at: http://www.amcp.org/data/jmcp/728-740.pdf 30. Choudhry NK, Shrank WH, Levin RL, et al. Measuring concurrent adherence to multiple related medications. Am J Manag Care. 2009;15(7):457-64.

31. Jha AK, Aubert RE, Yao J, Teagarden JR, Epstein RS. Greater adherence to diabetes drugs is linked to less hospital use and could save nearly $\$ 5$ billion annually. Health Aff (Millwood). 2012;31(8):1836-46. 
32. Chapman RH, Benner JS, Petrilla AA, et al. Predictors of adherence with antihypertensive and lipid-lowering therapy. Arch Intern Med. 2005;165(10):1147-52.

33. Choudhry NK, Setoguchi S, Levin R, Winkelmayer WC, Shrank WH. Trends in adherence to secondary prevention medications in elderly post-myocardial infarction patients. Pharmacoepidemiol Drug Saf. 2008;17(12):1189-96.

34. Basak R, McCaffrey DJ III, Bentley JP, Przybyla SM, West-Strum D, Banahan BF. Adherence to multiple medications prescribed for a chronic disease: a methodological investigation. J Manag Care Spec Pharm. 2014;20(8):815-23. Available at: http://www.amcp.org/WorkArea/ DownloadAsset.aspx?id=18371.

35. Qaseem A, Humphrey LL, Sweet DE, Starkey M, Shekelle P; Clinical Guidelines Committee of the American College of Physicians. Oral pharmacologic treatment of type 2 diabetes mellitus: a clinical practice guideline from the American College of Physicians. Ann Intern Med. 2012;156(3):218-31.

36. Inzucchi SE, Bergenstal RM, Buse JB, et al. Management of hyperglycemia in type 2 diabetes: a patient-centered approach: position statement of the American Diabetes Association (ADA) and the European Association for the Study of Diabetes (EASD). Diabetes Care. 2012;35(6):1364-79.

37. IMS Health. IMS National Prescription Audit Database, December 2009.
38. Q1Medicare.com. 2009 Medicare Part D program information. February 18, 2015. Available at: http://www.qlmedicare.com/PartD-The-2009Medicare-Part-D-Outlook.php. Accessed June 26, 2015.

39. Sacks NC, Burgess JF Jr, Cabral HJ, Pizer SD, McDonnell ME. Cost sharing and decreased branded oral anti-diabetic medication adherence among elderly Part D Medicare beneficiaries. J Gen Intern Med. 2013;28(7):876-85.

40. Nau, DP. Proportion of days covered (PDC) as a preferred method of measuring medication adherence. Pharmacy Quality Alliance. Available at: http://ep.yimg.com/ty/cdn/epill/pdcmpr.pdf. Accessed June 26, 2015.

41. Huber CA, Schneeweiss S, Signorell A, Reich O. Improved prediction of medical expenditures and health care utilization using an updated chronic disease score and claims data. J Clin Epidemiol. 2013;66(10):1118-27.

42. Von Korff M, Wagner EH, Saunders K. A chronic disease score from automated pharmacy data. J Clin Epidemiol. 1992;45(2):197-203.

43. Fishman PA, Shay DK. Development and estimation of a pediatric chronic disease score using automated pharmacy data. Med Care. 1999;37(9):874-83.

44. Gilmer T, Kronick R, Fishman P, Ganiats TG. The Medicaid Rx model: pharmacy-based risk adjustment for public programs. Med Care. 2001;39(11):1188-202.

45. Sales AE, Liu CR, Sloan KL, et al. Predicting costs of care using a pharmacy-based measure risk adjustment in a veteran population. Med Care. 2003;4l(6):753-60. 
The Effects of Cost Sharing on Adherence to Medications Prescribed for Concurrent Use:

Do Definitions Matter?

APPENDIX A OAD Prescriptions Dispensed in 2009, by Class and Branded Versus Generic

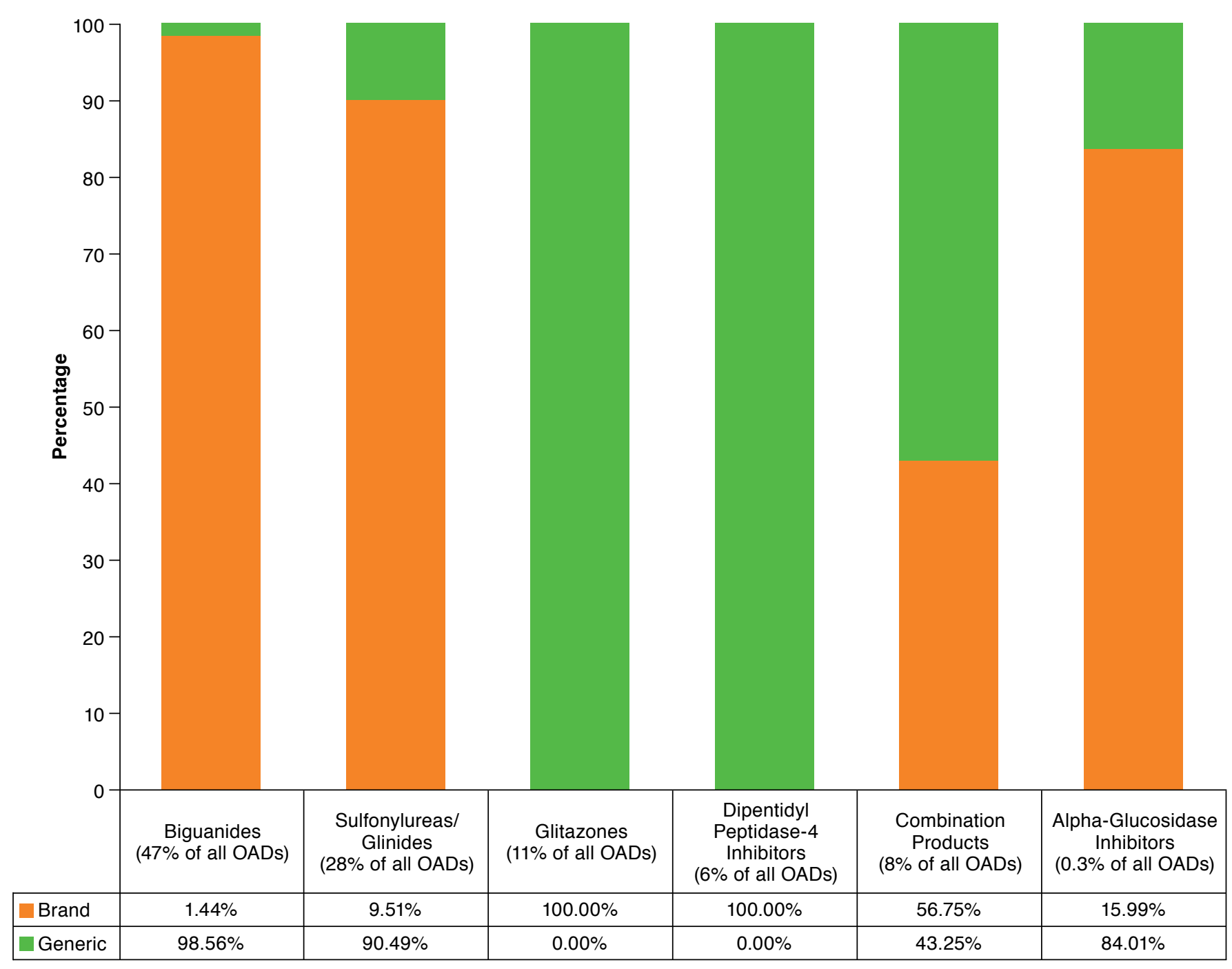

Source: IMS Health National Prescription Audit, 2009.37

$O A D=$ oral antidiabetic. 
The Effects of Cost Sharing on Adherence to Medications Prescribed for Concurrent Use:

Do Definitions Matter?

APPENDIX B Characteristics of Unmatched and Matched Samples ${ }^{a}$

\begin{tabular}{|c|c|c|c|c|c|c|c|c|}
\hline \multirow[b]{3}{*}{ Patients, n (\%) } & \multicolumn{4}{|c|}{ Unmatched Sample } & \multicolumn{4}{|c|}{ Matched Sample } \\
\hline & \multicolumn{2}{|c|}{ Part D Standard } & \multicolumn{2}{|c|}{ Part D Subsidy } & \multicolumn{2}{|c|}{ Part D Standard } & \multicolumn{2}{|c|}{ Part D Subsidy } \\
\hline & 81,047 & (35) & 150,359 & (65) & 19,027 & $(50)$ & 19,027 & $(50)$ \\
\hline Male, n (\%) & 37,672 & (46) & 46,271 & (31) & 12,412 & (35) & 12,430 & (35) \\
\hline Age, mean (SD) & 74.5 & $(6.34)$ & 74.5 & $(6.28)$ & 74.6 & $(6.42)$ & 74.5 & $(6.33)$ \\
\hline \multicolumn{9}{|l|}{ Region, n (\%) } \\
\hline East & 24,536 & (30) & 38,528 & (26) & 5,358 & $(28)$ & 5,358 & $(28)$ \\
\hline Midwest & 18,739 & $(23)$ & 20,796 & (14) & 2,924 & (15) & 2,964 & (15) \\
\hline South & 27,997 & (35) & 60,685 & $(40)$ & 8.017 & $(42)$ & 7,856 & (41) \\
\hline West & 9,775 & (12) & 30,352 & (20) & 2,742 & (14) & 2,849 & (15) \\
\hline Income, mean (SD) & $\$ 45,788$ & $(16,532)$ & $\$ 40,308$ & $(14,533)$ & $\$ 42,330$ & $(15,403)$ & $\$ 42,130$ & $(14,813)$ \\
\hline Risk score, mean (SD) & 5.09 & $(2.45)$ & 6.0 & $(2.75)$ & 5.66 & $(2.69)$ & 5.67 & $(2.70)$ \\
\hline \multicolumn{9}{|l|}{ Comorbid medication use, $\mathrm{n}(\%)$} \\
\hline Hypertension/cardiovascular disease & 73,571 & (91) & 141,348 & (94) & 17,943 & (94) & 17,957 & (94) \\
\hline Hyperlipidemia & 64,778 & $(80)$ & 121,415 & $(81)$ & 15,766 & $(83)$ & 15,757 & $(83)$ \\
\hline Mental health & 32,893 & $(41)$ & 75,799 & $(50)$ & 8,757 & $(46)$ & 8,826 & $(46)$ \\
\hline Medication burden, mean (SD) & 19.1 & $(9.93)$ & 24.3 & $(12.42)$ & 21.7 & $(11.16)$ & 21.9 & $(11.78)$ \\
\hline \multicolumn{9}{|l|}{ OAD use, $\mathrm{n}(\%)$} \\
\hline $1 \mathrm{OAD}$ & 40,572 & $(50)$ & 73,695 & (49) & 10,368 & $(54)$ & 10,321 & $(54)$ \\
\hline 2 OADs & 27,356 & (34) & 52,111 & $(35)$ & 6,075 & $(32)$ & 6,239 & (33) \\
\hline $3+$ OADs & 13,119 & (16) & 24,553 & (16) & 2,584 & (14) & 2,467 & (13) \\
\hline Insulin use, n (\%) & 12,316 & (15) & 27,103 & (18) & 2,714 & (14) & 2,748 & (16) \\
\hline \multicolumn{9}{|l|}{ Complexity, n (\%) } \\
\hline $1 \mathrm{OAD}$, no insulin & 34,765 & (43) & 60,474 & $(40)$ & 8,996 & $(47)$ & 8,946 & $(47)$ \\
\hline 2 OADs, no insulin & 23,145 & (29) & 42,913 & (29) & 5,204 & $(27)$ & 5,297 & (28) \\
\hline 3+ OADs and/or insulin & 23,137 & (29) & 46,972 & (31) & 4,827 & (25) & 4,784 & (25) \\
\hline \multicolumn{9}{|l|}{ OAD use, $\mathrm{n}(\%)$} \\
\hline Biguanides & 44,416 & $(55)$ & 79,837 & (53) & 10,671 & $(56)$ & 10,706 & $(56)$ \\
\hline Sulfonylureas/glinides & 39,957 & (49) & 76,546 & $(51)$ & 9,549 & $(50)$ & 9,692 & $(50)$ \\
\hline Glitazones & 17,576 & (22) & 34,809 & (23) & 3,583 & (19) & 3,629 & (19) \\
\hline Combination products & 8,518 & (11) & 16,208 & (11) & 1,673 & (9) & 1,686 & (9) \\
\hline DPP-4 inhibitors & 5,147 & (6) & 9,266 & $(6)$ & 946 & (5) & 866 & (5) \\
\hline Alpha-glucosidase inhibitors & 495 & $(0.6)$ & 1,124 & $(0.7)$ & 99 & $(0.5)$ & 99 & $(0.5)$ \\
\hline
\end{tabular}

